\title{
DIGITALCOMMONS
}

@WAYNESTATE -

Wayne State University

Social Work Faculty Publications

Social Work

4-1-2011

\section{"So I Just Took Over": African American Daughters Caregiving for Parents With Heart Failure}

Nancy Thornton

Wayne State University

Faith Pratt Hopp

Wayne State University, bb2938@wayne.edu

\section{Recommended Citation}

Thornton, N. \& Hopp, F.P. (2011). "So I just took over": African American daughters caregiving for parents with heart failure. Families in Society 92(2): 211-217. DOI: 10.1606/1044-3894.4103

Available at: http://digitalcommons.wayne.edu/soc_work_pubs/4 


\title{
"So I Just Took Over": African American Daughters Caregiving for Parents With Heart Failure
}

\author{
Nancy Thornton \& Faith Pratt Hopp
}

\begin{abstract}
This article examines the experiences of African American women who are caring for a parent with heart failure. Seven adult daughter caregivers completed in-depth, qualitative interviews, and a phenomenological approach was used for data analysis. Results suggest the presence of caregiving stressors, including heart failure symptoms and comorbidity, caregiving duties, social-emotional stressors, and distrust of the health system. Relevant coping strategies included valuing the caregiving role, coordinating care with siblings, taking charge, and spirituality. Social workers can play a critical role in supporting and advocating for caregivers of persons with heart failure, helping them to cope with stressors associated with advanced illness, connecting families with culturally acceptable services, and facilitating communication between families and health care providers.
\end{abstract}

\section{IMPLICATIONS FOR PRACTICE}

- Social workers can help to reduce racial health disparities by addressing barriers such as families' negative perceptions of hospitals, limitations in communication between health care providers and the individual's caregiver(s), and the lack of continuity of health care provided after hospital discharge.

$\mathbf{F}$ amilies struggle to meet the burgeoning care needs of elders with chronic illness that are sometimes complicated by the interplay of health conditions and factors of race/ethnicity, gender, and geographical location. The culture of African American families often stresses the importance of caring for family members within the home and avoiding institutional care, suggesting the essential role of caregiving for those with chronic illness (Turner, Wallace, Anderson, \& Bird, 2004). Heart failure is one chronic condition that poses particular challenges, because this condition has a particularly high prevalence in African American communities (Loehr, Rosamond, Chang, Folsom, \& Chambless, 2008).

Given the prominent role played by daughters in caring for chronically ill parents (Pandya, 2005; Pinquart \& Sorensen, 2005), the explicit role expectations for women in African American families regarding caregiving (Burton, 1996; Krieger, Rowley, Herman, Avery, \& Phillips, 1993; Samuel-Hodge et al., 2000), and the growing need for more culturally appropriate heart failure care (Fiscella \& Williams, 2004), there is a clear need for greater understanding of the daughters' experience in caring for older parents with heart failure. However, despite the importance of this issue, very little information is available on caregiving provided to persons with heart failure by African American daughters. Therefore, this study is based on an exploration of the lived experience of African American daughters caring for a parent with advanced heart failure, including stressors and coping strategies, as they navigate the health care system.

\section{Background}

Distinctive cultural family patterns contribute to the importance of caregiving in African American families. For example, compared with White or Hispanic women, African American women are less likely to have spouses (Farley \& Haaga, 2005), a factor that can contribute to greater caregiving responsibilities for the adult children of those with chronic illnesses. Practitioners and researchers should not discount the important role of male caregivers, who were found to compose 33\% of African American caregivers in one study (NavaieWaliser, Spriggs, \& Feldman, 2002). However, research suggests that African American women have a particularly important role in terms of the quantity, intensity, and complexity of caregiving duties (NavaieWaliser et al., 2001; Pandya, 2005) and in terms of explicit caregiving role expectations for women in African American families (Burton, 1996; Krieger et al., 1993; Samuel-Hodge et al., 2000). This emphasis on caregiving by African American women has been attributed to the historical need for informal support as a means of individual and group survival (Krieger et al.) and as integral to intergenerational helping roles (Burton; Samuel-Hodge et al.).

Existing caregiving literature has highlighted African American families' positive approach to caregiving (Farran, Miller, Kaufman, \& Davis, 1997) and the sense of reward that many experience through caregiving activities (White, Townsend, \& Stephens, 2000) despite limited access to health care and other support services (NavaieWaliser et al., 2001) and financial hardship (Pandya, 2005). Furthermore, some studies suggest that African American caregivers have less caregiving burden compared to Whites (Hinrichsen \& Ramirez, 1992; Knight, Silverstein, McCallum, \& Fox, 2000), which has been attributed to African American family strengths of valuing elders and the role of religion and spirituality (White et al.).

Heart failure is a major chronic illness that is particularly prevalent among older adults (American Heart Association, 2008b). It is a progressive condition in which the individual's need for blood and oxygen are not being met because the heart muscle is unable to pump enough blood through the heart. Congestive heart failure is a term to describe congestion in body tissues due to the slowing of the blood flow out of the heart and backing up of blood in the veins, leading to symptoms of swelling (edema), fatigue, and shortness of breath (American Heart Association, 2009). Heart failure is a major contributor to growing health care costs, as hospital discharges from heart failure increased 171\% from 1979 to 2005 (American Heart Association, 2008a).

Approximately $5 \%$ of those with symptomatic heart failure have advanced heart failure, indicating a progression of the disease to the 
TABLE 1. Parent and Daughter/Caregiver Descriptives

\begin{tabular}{|c|c|c|c|c|c|c|c|}
\hline Pair & $\begin{array}{c}\text { Parent / } \\
\text { daughter ages }\end{array}$ & $\begin{array}{l}\text { Dyad } \\
\text { relationship }\end{array}$ & $\begin{array}{l}\text { Parent education } \\
\text { (years) }\end{array}$ & $\begin{array}{l}\text { Parent marital } \\
\text { status }\end{array}$ & $\begin{array}{l}\text { Parent \& daughter } \\
\text { residence }\end{array}$ & $\begin{array}{l}\text { Daughter reported } \\
\text { health status }\end{array}$ & $\begin{array}{c}\text { Daughter reported serious } \\
\text { health conditions }\end{array}$ \\
\hline 1 & $80 / 47$ & Mother/daughter & 3 & Single & Separate & Very good & High blood pressure \\
\hline 2 & $76 / 52$ & Mother/daughter & 12 & Divorced & Together & Poor & Depression \\
\hline 3 & $65 / 44$ & Mother/daughter & 13 & Separated & Separate & Poor & Diabetes, back pain, etc. \\
\hline 4 & $67 / 39$ & Mother/daughter & 12 & Widowed & Together & Good & None reported \\
\hline 5 & $81 / 50$ & Mother/daughter & 12 & Widowed & Separate & Very good & Diabetes \\
\hline 6 & $66 / 45$ & Father/stepdaughter & 12 & Single & Separate & Good & None reported \\
\hline 7 & $74 / 40$ & Father/daughter & 11 & Widowed & Separate & Very good & Diabetes \\
\hline
\end{tabular}

Note. Race for all parent/daughter dyads is African American.

degree that there are clinical markers of persistent and severe symptoms (Adams \& Zannad, 1998). Although persons with advanced heart failure have challenges similar to those of older adults facing other serious chronic illnesses, heart failure has a less distinct and less predictable trajectory, compared with chronic diseases such as cancer (Murray, Kendall, Boyd, \& Sheikh, 2005). Moreover, although people with heart failure, like those with diseases such as dementia, face gradual physical and functional decline, they may also experience acute episodes from which they may recover.

In contrast with research on caregiving for conditions such as stroke and cancer, relatively few studies have focused on caregiving for persons with heart failure (Molloy, Johnston, \& Witham, 2005). Moreover, the small numbers of existing heart failure caregiving studies (e.g., Bennett et al., 2001; Evangelista et al., 2002; Kurylo, Elliott, DeVivo, \& Dreer, 2004) have focused on spousal caregivers. Within this literature, the caregiving experience of family members other than spouses has not been specifically examined (Molloy et al.), suggesting the need for more information on the experiences of adult daughter caregivers.

\section{Method}

\section{Study Design}

This study is based on interviews with informal caregivers of African Americans with advanced heart failure, taken from a larger qualitative study of the barriers and facilitators to heart failure care. Advanced heart failure was defined by the presence of (a) New York Heart Association class III or IV designation and/or (b) an estimated 1-year mortality of $32.5 \%$ or above, based on established mortality predictor algorithms (Lee et al., 2003). This study setting was in Detroit, a city that has experienced a severe population decline, racial segregation, high unemployment, poverty (e.g., Farley, Danziger, \& Holzer, 2000), and racial health disparities (Schulz, Williams, Israel, \& Lempert, 2002). All of these factors have an important impact on residents' quality of life (Polednak, 1997).

Sample. The study was approved by the institutional review board of Wayne State University with oversight for the community sample. The subsample for the present study includes 7 adult daughters, including 1 stepdaughter, from a total sample of 20 caregivers (including spouses and extended family members) who were interviewed for this project. Descriptive information on the sample is provided in Table 1.

Study procedures. We used a two step informed-consent process in which care recipients had the option of nominating a caregiver to be interviewed, and the caregivers signed an informed consent if they were willing to participate. Caregivers completed a questionnaire that covered basic demographic information and information on the degree of care they provided. Interviews were held in 2008, conducted by research assistants in the home of either the caregiver or the parent. One of the assistants, who conducted three of the interviews, was an African American woman who held an advanced degree in anthropology and who had also personally experienced heart failure. The other research assistant, who conducted four of the interviews, was a White social work doctoral student. The interviews were audiotaped, and the caregivers received a $\$ 50$ gift card for participating. Interview questions are shown in the Appendix.

Analysis. A phenomenological approach was used in the design of this study to identify the participant's perceptions and meaning of their lived experience. A thematic analysis was conducted by the researchers based on data obtained through the questions asked in the caregiver interview as well as the topics introduced by the participants. The interpretative process started with listening to the recordings of the interviews and an initial reading of the transcripts to develop an overall grasp of the material. Data were first analyzed using an open coding procedure, by identifying meaningful units of information in segments of phrases, sentences, or lines. These units were assigned a code, and all possible codes identifying meanings, variations, and commonalities were included in this phase. The reoccurring codes were then clustered according to similarities and relationships and condensed into initial categories. Charts were developed to graphically display and organize the data, displaying each initial category, the associated participant, and specific quote. The text was then recoded specifically for the subthemes that emerged, and the major themes were then identified.

After this organizational phase, the text was then evaluated again, taking into account the research question, initial readings, the meaning units, themes, and literature. From this process we developed generalizations related to the shared experiences of these women. These are identified as the final themes and subthemes of this study. Observer triangulation and peer debriefing were among the strategies we used to ensure rigor and address "threats to trustworthiness" (Padgett, 2008, p. 184) such as researcher bias. Retention of the raw data and ongoing documentation of data analysis decisions, in the form of charts and notes during the process, provided a decisionmaking trail.

\section{Results}

Two main themes were identified through the analysis process: caregiving stressors and caregiving coping strategies. Subthemes related to both stressors and coping strategies are discussed in the following sections.

\section{Theme I: Caregiving Stressors}

Caregiving stressors, the first of the two major themes, were identi- 
fied as any events in the life of the caregiver that resulted in caregiver strain or anxiety.

Heart failure symptoms and comorbidity. Heart failure symptoms represent an indication or sign of heart disease experienced by an individual. Comorbidity indicates the presence of another illness or disease. Attending to the symptoms of advanced heart failure was a concern of all of the caregivers interviewed. One daughter, who experienced caregiving for both of her parents with heart failure, stated: "You know, not being able to catch your breath and different stuff and the fluid building up. It's no joke...the sickness and death." Caregivers also described their parents' cognitive symptoms of memory loss and fatigue. They were familiar with the cycle of exacerbation, hospitalization, and subsequent recovery that is typical of the heart failure trajectory. Another respondent explained that when her father's health started to decline "he started talking about what he wanted in his obituary... he had been in the hospital... and he was having a lot of problems then," but explained his subsequent recovery as "[he] got himself going."

The caregivers spoke of multiple chronic illnesses experienced by their parents, which included cancer and diabetes. These illnesses often required home nursing care to address symptoms, and daughters administered medications and completed other medical tasks for their parents. The caregivers' experience with heart failure symptoms and comorbidity gives insight into the stressors particular to these illnesses.

Caregiving duties. This subtheme comprises a range of tasks completed by caregivers for their parents, often out of a sense of obligation. Caregivers provided help to their parents with personal needs including feeding, bathing, dressing, toileting, transferring, administering medications, and dealing with incontinence. Communicating with health care providers and providing transportation to medical appointments were significant portions of the caregiving responsibilities. They also managed household tasks, such as shopping, food preparation, and house cleaning. One daughter, who lives separately from her father, minimized the work she does for him, saying, "He doesn't take up that much of my time. I do his laundry, clean his apartment, cook, set up his medication. I would take him...to all his doctors appointments."

The daughters also described responding to the emotional needs of their parents in their caregiving, such as keeping their parents calm through their daily routine. Although sometimes it seemed that it would have been easier to do everything themselves, the daughters tended to be sensitive to their parents' loss of independence with advancing illness and described their efforts to help their parents have some control and decision making in their daily lives. One daughter stated, "So some things he's doing good where he can do himself, and that's more better, you know, to give him a little independence, where he's not like solely dependent on me."

Another caregiving responsibility identified by the daughters was providing for the socialization needs of their parents. Caregivers noted that their parents tended to stay in their homes unless they were going to a medical appointment, and it took great effort on their part to arrange other activities, because of their parents' fatigue and limited mobility. A caregiver recounted telling her mother, "You've been cooped up in this house other than going to the doctor's office.'...I took her out and she had a really good time....You just can't sit in the house all the time. It's depressing." The actual duties of care, then, represented a variety of tasks that were performed with sensitivity to their parents' emotional needs.

The daughters tended to see it as their duty to financially support their parents. There were financial sacrifices, as parents had medications prescribed that were not covered by Medicare, Medicaid, or insurance, or they had so many prescriptions that even the copays became unaffordable. Caregivers acknowledged the hardship of helping with the medical expenses, but described a determination that their parents would get their needed medical care.

Social-emotional stressors. Social-emotional stressors describe the caregiver's personal feelings in their caregiving role and represented a range of situations or problems for the caregivers, including sacrificing for their parent, protecting them, anticipating a loss, being homebound, and experiencing interpersonal conflicts.

Sacrifices made to care for their parents was expressed by one caregiver as, "Well, I don't expect everybody to do what I do...but I kind of put my life on hold to take care of my mother." This caregiver also described her own emotional state as being dependent on her mother's functioning, "If she's feeling good, then I'll feel good... when she's having a bad day, it makes me have a bad day." The caregivers tended to frame their sacrifices positively and sometimes expressed the desire to do more caregiving. For example, one daughter mentioned that "if I was really financially able to just take care of her $24 / 7$...I would do that every day, sunup, sundown."

In their protectiveness of their parents, caregivers relied on relatives and close friends. Daughters tended to respect their parents' wariness of strangers and planned accordingly. When one caregiver was asked about needed support, she replied, "If I had some more siblings. If they were like me." This caregiver also described being homebound, because of fears related to her parent's medical condition, stating, "I can't leave...or, I won't leave. I might run to the corner store or something. But as far as going out on a date or just going to the movies."

The anticipated death of their parents as heart failure progressed was difficult for the daughters. The daughter who had recently lost her mother to heart failure expressed difficulty coping with her father's hospitalizations, which made her fear that "I'm about to lose my father just like I lost my mother." In spite of her mother's decline, another caregiver remarked, "well, she can't remember...but she still sharp up there." A sense of helplessness was sometimes associated with this loss, and caregivers expressed sadness that the health professionals could not cure their parents.

Interpersonal conflicts sometimes occurred, which brought difficult dynamics to already stressful caregiving situations. One caregiver was very aware of her situation as a less-favored child in her relationship with her mother, saying "she needs help...everybody else walked out and I'm here. I'm the one who never was her favorite, but the one who is taking care of her now. That's where I am." The amount of time devoted to caregiving could also cause problems, with caregivers' spouses feeling neglected. Being the subject of their parents' irritability was hard for caregivers, and some described feeling worn down by this, with one saying, "I've went in my room, and I've cried. I'll have a cry. And then once I do that, I'm all right and I'm ready for the next round."

Distrust of the health care system. Many of the caregivers described having concerns about their parents' health care practitioners, and some reported a lack of confidence in the quality of hospital care. Because of their suspicions, many caregivers held a vigilant and critical stance toward the health care system. The specific complaints about the hospitals included long waiting times in emergency rooms, lack of responsiveness from attendants, and lack of cleanliness. The caregivers clearly empathized with their parents' resistance to going to their medical appointments or hospitalizations. As one caregiver put it, "For me, I hate when she goes to the doctor, because it just seems like every time she goes, he just puts her in [the hospital], and 
she hates it....I mean, who wants to go?" Caregivers often felt that they did not receive appropriate communication from health care providers, and they sometimes questioned the treatment prescribed, as this daughter expressed:

The doctors, to me, are quick to give you prescriptions for this, prescriptions for that. My mother was on... at least 15 pills a day, too much medicine.... think a lot of times, as you get older, they're quick to give you prescriptions just to pacify you or modify the pain you have, instead of really trying to get to the root of the problem.

There was little recognition of support from social workers or health care providers. In response to a question about experiences with social workers, caregivers reported either having no contact, being unsure whether or not they received any social work services, or receiving minimal services. An example of minimal services is described by one daughter as receiving help with utilities, but she noted that "there's nothing else; nothing extra, just the basic...a little food stamps or something like that, but not even that many of that."

Many participants expressed reluctance to place their parents in a nursing home. For example, one caregiver stressed, "I would never put her in a nursing home." The daughters were also reluctant to use home health care providers, generally attributing it to their belief that their parents did not want strangers in their home. Therefore, instead of being a source of support, the health care system would often provide more stress as the caregivers assumed a guarded stance against this perceived source of risk.

\section{Theme II: Caregiver Coping Strategies}

Caregiver coping strategies are defined as those plans or actions that caregivers use to deal successfully with a difficult problem or situation regarding their parents' advanced heart failure.

Valuing the caregiving role. The subtheme of valuing the caregiving role refers to the realization of caregivers themselves of the worth of their role and the importance of providing care to their parents. This was apparent as the caregivers tended to thoughtfully describe the qualities needed for a person to fulfill the caregiving role and appeared to have carefully considered these qualities, including patience, compassion, and tolerance. A caregiver stated: "You have to be humble. Pay attention to the breathing. Pay attention to everything... the walking. You have to just pay close attention."

Caregivers readily identified the benefits of caregiving, and several caregivers experienced the existing or growing strength of the relationship between themselves and their parents as the primary benefit, such as, "Before, it wasn't like that. We never said we loved each other to each other or anything, but now it's totally different." Daughters described satisfaction with the harmony between themselves and their parents, or feeling that their relationship with the parent was special, different from the parent's relationship with their siblings. Their esteem for their parents was apparent, as the daughters clearly identified the importance of their parents' welfare and satisfaction with the care they gave. Another benefit described was the medical knowledge gained that might prevent the caregivers from experiencing health problems like their parents.

Several daughters reported receiving recognition from others in their community for their caregiving. This recognition was very important to the caregivers and seemed to help sustain them in their difficult vocation. As one caregiver explained, “There's a lot of people with kids and they be telling her, 'Oh, I wish I had your daughter for a daughter,' because I take care of my mother.” Valuing the caregiving role, evidenced by reflecting on caregiving qualities, identifying benefits, and accepting community validation for caregiving, helped the caregivers cope with the stressors of their work.

Coordination of care with siblings. Coordination of care with siblings required consistent communication and effort on the part of the primary caregiver. One caregiver described her work in keeping an out-of-state sibling involved in her mother's treatment. Another caregiver referred to her brothers and sisters and said "I do not make any decision without talking to all of them...everybody knows everything before any decision was made." Gender played a role in the coordination of caregiving tasks between siblings, described by one daughter as:

It's just me and my brother...so there's a lot of things that he can't do, being a man. But he helps out like to take her to the doctor, to the foot doctor. Medical doctors, I usually take her because I help her get undressed. To the eye doctor and things like that, he'll come and take her. But usually it's me. I'm doing the majority of everything.

Although the daughters in this sample assumed the primary caregiver role and did most of the actual caregiving labor, they also worked to involve siblings and cooperated with them regarding both daily care and more complex housing and medical decisions.

Taking charge. The caregivers in this study described how they "took charge" through their initiative, decisiveness, and readiness to assume the multiple responsibilities of the caregiving role. One caregiver described her efforts in caring for her mother, who needed constant care because of the severity of her illness, by describing an exhausting list of responsibilities and saying, "basically, that's it. I do everything." This daughter also gave evidence of taking on her mother's serious health issues as her own: "So we have a multitude of problems." Another caregiver explained a complicated care transition with the statement, "I knew he needed someone to care for him....so I just took over."

A major concern among several participants was the need to make housing arrangements. Sometimes these arrangements involved having their parents moving in with them; while others were involved in planning for the provision of long-term care to accommodate their parents' declining physical status. They often saw limited options, other than moving their parents in with them, because the caregivers felt that neither senior housing nor nursing homes were acceptable options. At times the arrangements included modifying their homes to add or improve accessibility in adapting to the declining strength and mobility of their parents.

As they took charge of the care needs of their parents, the caregivers generally tended to respond with compassion to their parents' situation, even in the most stressful times. When asked to identify the challenges of caregiving, most of the daughters responded with empathy regarding the suffering of their parents (rather than identifying the personal cost or burden of caregiving) with comments such as, "just watching her being sick...the way it has really affected her." This compassion was not limited to their own parents; for example, after describing her frustration with the health care system and the unmet needs of persons with chronic illness she had observed in accompanying her parent to medical appointments and hospitalizations, one daughter said: 
It is really hard for them and this is not fair. It's not fair at all.... You don't have anybody to fight for you or talk for you. I'll talk for my mom, but it's not just my mom. There's a lot of moms out here that don't have anybody.

Taking charge, then, involved leadership within the family and seemed to be spurred by lack of trust in the health care system and lack of support from health care providers. This approach seemed to be critical to the caregiving process, representing the attitude with which caregiving was assumed, generally in both a practical and empathic manner.

Spirituality. Caregivers also credited their religion or expressed thoughts that were spiritual in nature. One caregiver attributed the positive resolution of several health crises to her faith, expressed as: "I just give it to the grace of God...because it's just like the Lord is just working, and just coming." Caregivers tended to express gratitude for even small achievements, as expressed by one caregiver who said, "I'm just blessed if she wakes up and has a good day." Caregivers also talked about their struggles to hold on to their faith, their acceptance of the situation, and the use of prayer to cope with their parents' illnesses and the daily demands of caregiving. Spirituality was clearly a very real component of caregiving and helped the caregivers cope with the stressors of their daily life and find meaning in their work.

\section{Discussion}

The African American daughters in this study revealed a multitude of stressors as they witnessed their parents experience the symptoms of heart failure and comorbid illnesses, fulfilled their caregiving duties, encountered social-emotional stressors, and experienced distrust of the health care system. The high esteem that the caregivers held for their parents was evident as they prioritized their parents' needs, deferred to their parents' preferences for care at home, and tried to reinforce their parents' independence. They also used a variety of coping strategies, including valuing the caregiving role, coordinating care with siblings, taking charge, and drawing on spirituality as a means of meeting the daily demands of parental care.

Previous studies have highlighted the importance of kinship care in the African American communities (e.g., Morris \& Edwards, 2006), the value accorded caregiving by African American families, and the importance placed on maintaining elders in the home and avoiding nursing home care (Groger, Mayberry, \& Straker, 1999; Sterritt \& Pokorny, 1998). The present study builds on this previous work by suggesting the conscious and consistent efforts of caregivers to coordinate care and share responsibilities among siblings. The primary caregivers, who clearly performed the bulk of the caregiving duties, were generally careful to include siblings in the process of meeting their parents' care needs and included siblings in treatment decisions. The value placed on this sibling cooperation was clear and seemed to be based on protecting parents, given that they distrusted those outside of the family system.

In the families represented by this sample, the daughters of the sibling groups assumed the primary caregiving responsibilities. Although the daughters were all caring for one parent at the time of this study, some of them had previously provided care for their other parent, who had since died of chronic illness. The daughters often had competing demands of employment and managing their own families. This social phenomenon was described decades ago, when Stoller (1983) pointed to Friedan's use of the term "superwoman squeeze" (p. 857) in reference to the competing demands on women as they parent their children, care for aging parents, and work outside of their home. Similarly, Sterritt and Pokorny's study of caregiving in African American families observed that caregiving was considered to be a women's role alone, which suggests that many women take on multiple caregiving roles with little outside support.

Our study confirms that caregivers approached the responsibility they assumed in an active manner, taking charge of their parents' needs. This was an approach that served the caregivers well, as they coped with the stressor of mistrust of the health system and monitored their parents' care, made decisions, challenged authority, and advocated for their parents. Although the strength of the African American woman in the caregiving role has been described in the literature (Chadiha, Adams, Biegel, Auslander, \& Gutierrez, 2004) this study highlights how these women channel this strength in their vigilance over their parents' health care.

The caregiving daughters encountered significant stressors, some of which were associated with the trajectory of advanced heart failure (Murray et al., 2005). As described by some of these daughters, caregivers may find that their care recipients survive several exacerbations with intensive treatment, but with gradually deteriorating functioning. Hospital care, then, becomes a routine and unpleasant component of advanced heart failure caregiving. Progressive deterioration is also difficult for the caregivers, as they witness their parents' loss of functioning and ability to be present with them in the lonely experience of caregiving. The actual death of an individual with advanced heart failure is often unexpected by those caring for them (Murray et al.). Many of the caregivers in this study described feeling isolated and identified only minimal personal support, and this suggests that they may have a difficult grief process in the probably unexpected, yet eventual, death of their parents.

The daughters made emotional sacrifices to meet the intensive caregiving demands. Although the daughters involved siblings in their parents' care, several seemed to feel very alone in their work, without sufficient respite. The isolation experienced by some of these daughters in their caregiving role was also present in a study of individuals with advanced heart failure and their spousal caregivers by Aldred, Gott, and Gariballa (2005), who reported that the caregivers of spouses with heart failure had difficulty leaving home because of the spouses' care needs. They also found that there was little support available to the caregivers, because friends and other family members who were potential caregivers were often in need of help themselves.

Many of the caregivers participating in this study were critical of the health care system and tended to look warily at the system's involvement in their parents' care. Caregivers spoke of instances of inadequate care and often questioned the treatment their parents received. The distrust noted among some of the African American women toward health care professionals and hospitals is consistent with reported attitudes and beliefs, based on historical events and social factors that have long influenced the perceptions in the African American community. Among these events and factors is "the specter of Tuskegee" (Gamble, 1997, p. 1773) and the current racial and health and ethnic disparities in health care that include lower quality treatment and diagnostic services (Smedley, Stith, \& Nelson, 2003). Smedley et al. also found "evidence that stereotyping, biases, and uncertainty on the part of healthcare providers can all contribute to unequal treatment" (p. 1). A phenomenon of distrust of health care providers by African Americans was also noted by Edmonds (1999), who described a "suspicion of the dominant culture and its institutions" 
(p. 27) and reliance on self-care, kinship care, and religious beliefs for relief from illness and pain as an alternative to reliance on the formal health care system.

Several limitations to this study should be noted. First, although efforts were made to ensure rigor, reactivity (Padgett, 2008) was a concern in that the caregivers were aware that their interview was part of a larger study on heart failure care, and they could have reacted with an emphasis on their commitment to facilitating care. Second, the study design required that each caregiver be referred by a parent experiencing advanced heart failure who was participating in the study. These caregiving daughters were therefore a small $(n=7)$ and selfselected group who had parents who felt healthy enough to participate in the research. Quite possibly, despite their critical stance toward the health care system, the caregivers we interviewed may actually have been more satisfied with their parents' health care than those who chose not to participate. Finally, with reference to Padgett's strategies to ensure rigor, we did not include prolonged engagement, negative case analysis, or member checking in our study design or analysis.

\section{Implications for Social Work Practice}

The distress experienced by the women in this study as they faced the difficult care needs and the eventual loss of their parents was compounded by the fact that caregivers often did not perceive that they were supported by social workers or health care professionals. The caregivers in this study seemed unaware of the existence of medical social workers, who might be in a position to provide psychosocial support and intervention during their medical crises. Social work intervention could have ameliorated the feelings of helplessness and experiences of isolation described by some of the caregivers in this study. The need for professional support was identified by Chadiha et al. (2004) in their review of African American women as informal caregivers, who noted that

social workers must not mistake the strong coping that serves as a strength to African American women in challenging caregiving circumstances to mean they are invulnerable to powerlessness and do not need formal resources. (p. 101)

Social workers and health care professionals can play a key role in empowerment and advocacy (National Association of Social Workers [NASW], 2001), intervening in ways that may reduce the distrust and open the lines of communication to ensure that the family's needs are identified and met during the intense and often unpredictable course of heart-related illness. The information obtained in this study adds to the growing literature on strategies of family empowerment, especially of diverse populations, as a means of bridging the barriers confronting families who are caring for elder family members. These social work strategies include those focusing on family strengths as opposed to the pathology, linking families with support systems, and interacting with clients using a "nonhierarchical, nonpowerful stance" (Pinderhughes, 1995, p. 138).

Another key role for social workers is to call attention to African American cultural strengths, including intergenerational kinship, multigenerational families, and respect for the elders (Turner et al., 2004). Damron-Rodriguez, Wallace, and Kingston (1994) provided a particularly useful framework for service providers that emphasizes accessible and culturally acceptable geriatric services for diverse populations. The cultural competence of social workers can be fur- ther developed with reference to Waites's (2009) intergenerational solidarity framework for African American families. This framework involves the use of an empowerment approach that draws on discussions of traditions, relationships, history, family member responsiveness, family roles, and family resources. The present study of African American caregiving daughters suggests that such frameworks could be made relevant for the care of elders dealing with chronic disease by an additional emphasis on valuing the caregiving role, coordinating care with adult siblings, and drawing on spiritual strengths.

Since caregivers often expressed dissatisfaction with the health care their parents were receiving, it may be beneficial to focus future social work research and practice on the specific barriers that exist between the African American community and the health care system. These barriers include negative perceptions of hospitals, limitations in communication between health care providers and the individual's caregiver(s), and the lack of continuity of health care provided after hospital discharge. These communication challenges may be at least partially resolved by following the recommendation made by Saunders (2003), that the care provider and the individual with heart failure should be treated "as one" (p. 138). Social workers should constructively work with other health care providers to address these barriers as a means of reducing racial health disparities.

The policy recommendations of NASW in response to the "family caregiving crisis" (Briar \& Kaplan, 1990) continue to be relevant today. The recommendations could help these caregiving daughters, because they advocate for full financial support and remuneration for family caregiving; educating the public through multimedia campaigns about the emotional stress of caregiving; and providing resources for in-home and out-of home care, household assistance, support groups, specific training, and transportation. NASW also suggested education to promote equal sharing of caregiving responsibilities between men and women, which would apply to the unequal caregiving experience of the adult sons and daughters. Further research is needed to examine the extent to which individuals with chronic illness are aware of social work support, and to determine if information on these services could be better disseminated in health care settings. By advocating for social policies that support these aims, social workers can play a vital role in helping to address complex issues regarding financial, physical, social, and emotional support faced by the growing number of adults caring for aging parents with chronic diseases such as heart failure.

\section{Conclusion}

This study of African American caregiving daughters of parents with advanced heart failure provided the opportunity to observe the unique challenges faced by families, as well as their strengths and resources for coping with the challenges of the urban health care system. Within this context, examination of the lived experiences of these daughters gives insight into the interplay of cultural expectations and gender roles and their effects on the caregiving for the growing number of vulnerable elders.

The results from this study contribute to the social work knowledge base by identifying caregiving coping strategies that build on strengths within the African American community. Social workers can play a critical role in supporting these strengths by advocating for social policies that support older persons with heart failure and their caregivers, and by helping families to deal with stressors associated with heart failure. Social workers can also make an important contribution to the provision of culturally sensitive care by connecting 
families with culturally acceptable services, such as in-home care, and facilitating better communication between families and health care providers to reduce feelings of alienation and distrust.

\section{References}

Adams, K., \& Zannad, F. (1998). Clinical definition and epidemiology of advanced heart failure. The American Heart Journal, 135(6), S204-S215.

Aldred, H., Gott, M., \& Gariballa, S. (2005). Advanced heart failure: Impact on older patients and informal carers. Journal of Advanced Nursing, 49(2), 116-124.

American Heart Association. (2008a). Heart disease and stroke statistics. Retrieved February 16, 2009, from http://www.americanheart.org/downloadable/ heart/1200078608862HS_Stats\%202008.final.pdf

American Heart Association. (2008b). Heart failure. Retrieved February 16, 2009, from http://www.americanheart.org/presenter.jhtml?identifier=1486

American Heart Association. (2009). What is heart failure? Retrieved from http:// www.americanheart.org/presenter.jhtml?identifier $=337$

Bennett, S. J., Perkins, S. M., Lane, K. A., Deer, M., Brater, D. C., \& Murray, M. D. (2001). Social support and health-related quality of life among heart failure patients. Quality of Life Research, 10, 671-682.

Briar, K. H., \& Kaplan, C. (1990). NASW Commission on Family and Primary Associations, technical assistance report: The family caregiving crisis. Silver Spring, MD: National Association of Social Workers.

Burton, L. (1996). Age norms, the timing of family role transitions, and intergenerational caregiving among aging African American women. Gerontologist, 36(2), 199-208.

Chadiha, L. A., Adams, P., Biegel, D. E., Auslander, W., \& Gutierrez, L. (2004). Empowering African American women informal caregivers: A literature synthesis and practice strategies. Social Work, 49(1), 97-108.

Damron-Rodriguez, J., Wallace, S., \& Kingston, R. (1994). Service utilization and minority elderly: Appropriateness, accessibility and acceptability. Gerontology and Geriatrics Education, 15(1), 45-63.

Edmonds, M. (1999). Serving minority elders: Preventing chronic illness and disability in the African American elderly. In M. L. Wykle \& A. B. Ford (Eds.), Serving minority elders in the 21st century (pp. 25-36). New York: Springer.

Evangelista, L. S., Dracup, K., Doering, L., Westlake, C., Fonorow, G. C., \& Hamilton, M. (2002). Emotional well-being of heart failure patients and their caregivers. Journal of Cardiac Failure, 8(5), 300-305.

Farran, C. J., Miller, B., Kaufman, J., \& Davis, L. (1997). Race, finding meaning, and caregiver distress. Journal of Aging and Health, 9(3), 316-333.

Farley, R., Danziger, S., \& Holzer, H. J. (2000). Detroit divided. New York: Russell Sage Foundation.

Farley, R., \& Haaga, J. (2005). The American people: Census 2000. New York: Russell Sage Foundation.

Fiscella, K., \& Williams, D. R. (2004). Health disparities based on socioeconomic inequities: Implications for urban health care. Academic Medicine, 79(12), 1139-1147.

Gamble, V. N. (1997). Under the shadow of Tuskegee: African Americans and health care. American Journal of Public Health, 87(11), 1773-1778.

Groger, L., Mayberry, P., \& Straker, J. (1999). What we didn't learn because of who would not talk to us. Qualitative Health Research, 9(6), 829-835.

Hinrichsen, G. A., \& Ramirez, M. (1992). Black and White dementia caregivers: A comparison of their adaptation, adjustment, and service utilization. Gerontologist, 32(3), 375-381.

Knight, B. G., Silverstein, M., McCallum, T. J., \& Fox, L. S. (2000). A sociocultural stress and coping model for mental health outcomes among African American caregivers in southern California. Journals of Gerontology Series B: Psychological Sciences and Social Sciences, 55, 142-150.

Krieger, N. N., Rowley, D. L., Herman, A., Avery, B., \& Phillips, M. (1993). Racism, sexism, and social class: Implications for studies of health, disease, and wellbeing. American Journal of Preventive Medicine, 9(Suppl. 6), 82-122.

Kurylo, M., Elliott, T. R., DeVivo, L., \& Dreer, L. E. (2004). Caregiver social problem solving abilities and family member adjustment following congestive heart failure. Journal of Clinical Psychology in Medical Settings, 11(3), 151-157.

Lee, D. S., Austin, P. C., Rouleau, J. L., Liu, P. P., Naimark, D., \& Tu, J. V. (2003). Predicting mortality among patients hospitalized for heart failure: Derivation and validation of a clinical model. JAMA, 290, 2581-2587.

Loehr, L. R., Rosamond, W. D., Chang, P. P., Folsom, A. R., \& Chambless, L. E. (2008). Heart failure incidence and survival (Atherosclerosis Risk in Communities Study). American Journal of Cardiology, 101, 1016-1022.

Molloy, G. J., Johnston, D. W., \& Witham, M. D. (2005). Family caregiving and congestive heart failure. Review and analysis. European Journal of Heart Failure, 7, 592-603.
Morris, T., \& Edwards, L. (2006). Family caregivers. In I. M. Lubkin \& P. D. Larsen (Eds.), Chronic illness: Impact and interventions (pp. 255-284). Boston: Jones \& Bartlett.

Murray, S. A., Kendall, M., Boyd, K., \& Sheikh, A. (2005). Illness trajectories and palliative care. British Medical Journal, 330, 1007-1011.

National Association of Social Workers. (2001). NASW standards for cultural competence in social work practice. Retrieved November 27, 2009, from http:// www.socialworkers.org/practice/standards/NASWCulturalStandards.pdf

Navaie-Waliser, M., Fledman, P., Gould, D., Levine, C., Kuerbis, A., \& Donelan, K. (2001). The experiences and challenges of informal caregivers: Common themes and differences among Whites, Blacks, and Hispanics. Gerontologist, 41(6), 733-741.

Navaie-Waliser, M., Spriggs, A., Feldman, P. H. (2002). Informal caregiving: Differential experiences by gender. Medical Care, 40(12), 1249-1259.

Padgett, D. K. (2008). Qualitative methods in social work research (2nd ed.). Thousand Oaks, CA: SAGE.

Pandya, S. M. (2005). Caregiving in the United States. Retrieved April 30, 2009, from the AARP Public Policy Institute, http://assets.aarp.org/rgcenter/il/ us_caregiving.pdf

Pinderhughes, E. (1995). Empowering diverse populations: Family practice in the 21st century. Families in Society: The Journal of Contemporary Human Services, 76(3), 131-140.

Pinquart, M., \& Sorensen, S. (2005). Ethnic differences in stressors, resources, and psychological outcomes of family caregiving: A meta-analysis. Gerontologist, 45(1), 90-106

Polednak, A. P. (1997). Segregation, poverty, and mortality in urban African Americans. New York: Oxford University Press.

Samuel-Hodge, C. D., Headen, S. W., Skelly, A. H., Ingram, A. F., Keyserling, T. C., Jackson, E. J....Elasy, T. A. (2000). Influences on day-to-day self-management of type 2 diabetes among African American women: Spirituality, the multicaregiver role, and other social context factors. Diabetes Care, 23(7), 928-933.

Saunders, M. M. (2003). Family caregivers need support with heart failure patients. Holistic Nursing Practice, 17(3), 136-142.

Schulz, A. J., Williams, D. R., Israel, B. A., \& Lempert, L. B. (2002). Racial and spatial relations as fundamental determinants of health in Detroit. Milbank Quarterly, 80(4), 677-707.

Smedley, B. D., Stith, A. Y., \& Nelson, A. R. (Eds.). (2003). Unequal treatment: Confronting racial and ethnic disparities in healthcare. Washington, DC: National Academies Press

Sterritt, P. F., \& Pokorny, M. E. (1998). African American caregiving for a relative with Alzheimer's disease. Geriatric Nursing, 19(3), 127-134.

Stoller, E. P. (1983). Parental caregiving by adult children. Journal of Marriage and Family, 45(4), 851-858.

Turner, W. L., Wallace, B. R., Anderson, J. R., \& Bird, C. (2004). The last mile of the way: Understanding caregiving in African American families at the end-oflife. Journal of Marital and Family Therapy, 30(4), 427-438.

Waites, C. (2009). Building on strengths: Intergenerational practice with African American families. Social Work, 54(3), 278-287.

White, T., Townsend, A., \& Stephens, M. A. (2000). Comparisons of African American and White women in the parent care role. Gerontologist, 40(6), 718-728.

\section{Appendix. Caregiver Interview Questions}

1. Suppose you met someone who just found out that someone they care about has been diagnosed with heart failure. How would you describe the illness to them?

2. What is the most challenging or difficult thing about having a parent with heart failure?

3. Besides yourself, does anyone else help your loved one with managing their illness?

4. What would help you to better care for your loved one with heart failure?

Nancy Thornton, LMSW, LPC, and Faith Pratt Hopp, MSW, PhD, assistant professor, Wayne State University. Correspondence: nancythornton.ypsi@gmail.com; School of Social Work, Wayne State University, 136 Thompson Home, 4756 Cass Ave., Detroit, Ml 48202

Manuscript received: August 19,2009

Revised: February 2, 2010

Accepted: February 22, 2010 